\title{
TODOS IGUAIS: O OBJETIVO DO ARTIGO 198 DO CÓDIGO DE PROCESSO CIVIL
}

\section{ALL EQUAL: ARTICLE 198 OF THE OBJECTIVE OF CIVIL PROCEDURE CODE}

\author{
Luciane Mara Correa Gomes ${ }^{1}$
}

\section{RESUMO}

A implantação do processo eletrônico no Brasil foi feita para ser um meio de minimizar a lentidão na tramitação dos processos. Criada a primeira barreira de desigualdade, pois não houve a adequação do sistema aos portadores de necessidades especiais. O Código de Processo Civil preconiza o tratamento isonômico ao impor ao Poder Judiciário o dever objetivo de acesso, distribuindo o encargo de instalação de salas de atendimento com suporte técnico e de pessoal a jurisdicionados, portadores de deficiência e idosos. Na falta do espaço físico, autoriza a lei a prática por meio físico, criando desequilíbrio na paridade de armas processual.

Palavras-chave: Paridade de armas, Processo eletrônico, Acessibilidade

\begin{abstract}
The implementation of the electronic process in Brazil was made to be a way to minimize the slowness in dealing with cases. Created the first barrier of inequality, because there was not the adequacy of the system to people with special needs. The Civil Procedure Code calls for equal treatment by imposing the Judiciary duty purpose of access, spreading the installation charge of treatment rooms with technical support and personnel to jurisdictional, disabled and elderly. In the absence of physical space, allows the law to practice through physical, creating imbalance in parity procedural weapons.
\end{abstract}

Keywords: Weapons parity, Electronic process, Accessibility

\footnotetext{
${ }^{1}$ Doutoranda em Sociologia pelo Instituto Universitário de Pesquisas do Rio de Janeiro - IUPERJ, Rio de Janeiro, (Brasil). Professora Auxiliar pelo Centro Universitário Augusto Motta e Professora Auxiliar da Faculdade Mercúrio, Rio de Janeiro, (Brasil). E-mail: lucianemara@uol.com.br
} 


\section{INTRODUÇÃO}

O presente artigo aborda o tema da implantação de política de igualdade com a instalação de espaço físico, com assistência presencial, nos órgãos do Poder Judiciário com insumos tecnológicos capazes de dar aos jurisdicionados acesso ao cumprimento dos atos processuais por meio digital.

A medida entrou no ordenamento jurídico a partir da Lei Federal n. 13.105, de 16 de março de 2015, em vigência desde 18 de março de 2016, que tem em seus artigos 198 e 199, a criação de um dever para o Poder Judiciário manter em todos os órgãos, ambiente capaz de suprir a necessidade de prática de atos processuais eletrônicos, como meio de conferir a paridade de armas.

O desenvolvimento do artigo está destinado a observar as consequências para o descumprimento do dispositivo legal como meio de produção de desigualdades entre as partes.

Este estudo busca investigar as estruturas fornecidas pelo Poder Judiciário para a prática dos atos processuais por meio eletrônico, com a hipótese de que se não houver a infraestrutura adequada, que lhe é imposta pela legislação processual, estará o Estado praticando uma violação ao princípio da economia e celeridade processual.

Verificar se o posicionamento do Conselho Nacional de Justiça tem se mostrado eficiente para o beneficiário da prestação jurisdicional, quando inexistente a infraestrutura, pois as alternativas conferidas pela legislação afetam diretamente os objetivos do processo eletrônico de ser uma via mais célere e menos dispendiosa para os interessados e para a sociedade.

Observar se as alternativas conferidas pelo legislador no caso de não possuir a infraestrutura física e de pessoal nos órgão judiciários é um mecanismo que evidencia a desigualdade entre as partes ao evidenciar barreiras econômicas. Na hipótese de não ser um fomento a desigualdade, averiguar se há paridade de armas como garantia de um processo justo para as partes ao criar meio distinto para a prática de atos processuais por meio não eletrônico para uma e para a outra por meio eletrônico. 
Estrutura-se o trabalho a partir de conceitos doutrinários deduzidos para os fins sociais e eficazes do processo eletrônico, como também a ponderação dos teóricos acerca da sua aplicabilidade e o confronto com a crise existente no campo judiciário para a lentidão na entrega da prestação jurisdicional.

A metodologia de trabalho se dá pela análise dos dispositivos normativos exarados pelo Conselho Nacional de Justiça, comparando-os com o Código de Processo Civil, uma vez que a vigência da Lei Federal n. 13.105, de 16 de março de 2015 ainda é recente para gerar um relatório pontual com dados e números para realização de uma pesquisa qualitativa, no que diz respeito à adoção da implantação das salas de atendimento para jurisdicionados nos órgãos judiciários.

$\mathrm{Na}$ conclusão, o trabalho aponta para as possíveis soluções do impasse da ausência técnica e de equipamentos para a acessibilidade, a partir da vigência da Lei Federal n. 13.105 , de 16 de março de 2015.

\section{PENSANDO EM REDUZIR BARREIRAS}

O novo Código de Processo Civil adequa a comunidade jurídica ao processo eletrônico, que ao ser inserido no ordenamento nacional em 2006 pela Lei Federal n. 11.419 , instituiu a via digital para a distribuição e processamento das demandas judiciais.

No entanto, a inserção do processo eletrônico não apagou as sequelas decorrentes de um país com um número elevado de excluídos digitalmente e que possuem potencial para o ajuizamento de uma demanda nos juizados especiais cíveis, fazendários ou federais, e não sejam dotados da capacidade de reproduzir uma prática que é desmaterializada.

Inserir o processo eletrônico no Brasil teve como finalidade a redução de acervo que causam urgências para espaço físico e recursos humanos para manuseio e realização de atos processuais.

O problema com o espaço para manutenção e guarda dos processos físicos, sempre foi um dos maiores entraves ao desenvolvimento célere dos atos processuais, bem como tornar mais ágil o intervalo de processamento de peças processuais e remessa aos gabinetes para 
despachos, pois a partir de qualquer computador, conectado ao sistema do tribunal, advogados, defensores públicos, promotores e juízes estariam habilitados a manusearem os processos.

Neste aspecto, a desigualdade que afetem as partes seria diminuída, quase extinta, pois não haveria barreiras ao acesso à prestação jurisdicional, contribuindo para o acesso de todos a uma ordem jurídica justa (PINHO, 2015, p. 421).

Todavia, no campo judiciário, há entraves que ultrapassam a seara legislativa, como será apontado neste trabalho, uma vez que a adoção de determinadas normas engloba a adaptação de sistemas de informática que atenderão a todos os jurisdicionados.

O artigo 198 do Código de Processo Civil cria para o Estado o dever, diante a obrigatoriedade da informatização dos processos, de assegurar que os interessados possam manejar os processos sem desigualdade de armas.

É oportuno salientar que enorme parte da população não conhece ou não utiliza um computador, ficando despreparada para a atuação no Poder Judiciário por conta de uma imposição legal.

Capaz de dotar seus agentes das fases e atualizações das ciências da informática, não deve o Estado fomentar a exclusão digital existente. Por esta razão, não deve recair sobre os administrados o ônus de adquirir equipamentos de informática e absorver as técnicas de utilização para garantir o acesso ao Poder Judiciário.

O Estado ao determinar que toda a estrutura de tramitação das demandas judiciais fosse adaptada para o processo eletrônico criou um custo financeiro para quem está inserido no campo judiciário e dividiu parte do seu trabalho social como a juntada de peças e documentos para os interessados no processo.

Cabe, num reequilíbrio de encargos, ao Estado conceder a quem teve o seu acesso à prestação jurisdicional os meios para este exercício da garantia constitucional, limitado ou impedido com a implantação do processo eletrônico.

E oportuno lembrar que, com o Código de Processo Civil, a todos será garantido o meio para a prática de atos processuais por meio eletrônico, incluindo aqueles que não 
possuem conhecimento tecnológico, idosos com mais de 60 anos e que não tenham habilidades com as tecnologias digitais, assim como os portadores de deficiência que, com o processo físico realizavam suas atividades de acordo com suas possibilidades, com equipamentos adequados e que, a partir do processo eletrônico, foram extirpados do exercício da advocacia e do acesso ao Judiciário, violando o princípio da inafastabilidade da prestação jurisdicional.

Esta afirmação é referendada por Marcacini (WAMBIER, 2015, p. 613) se posiciona que a postura do legislador, no momento presente:

(...) foi prudente, o alvitre do legislador, em determinar que sejam fornecidos nos fóruns equipamentos bastantes e suficientes para que sejam realizadas todas as atividades antes desempenhadas nos balcões e guichês judiciais, desonerando o jurisdicionado de suportar parte do custo da informatização pública.

É oportuno salientar que, à medida que o tempo transcorrer, os jurisdicionados superarão estas barreiras de acesso, uma vez que simplificada a tramitação, esta se faz econômica para a sociedade como um todo.

No que se refere ao fornecimento da garantia objetiva de acesso, Filho (CUNHA, et al, 2016, p. 416) relaciona que a disponibilização feita pelo Tribunal seja realizada da seguinte forma: "computadores ligados para a prática dos atos processuais bem como scanners para a digitalização dos documentos e peças necessários para a instrução das postulações realizadas".

Importante colocação é feita por Leonardo Greco a respeito da implantação do processo eletrônico (GRECO, 2015, p.315):

Cabem as ressalvas anteriormente realizadas no estudo das citações quanto à autenticidade dos documentos eletrônicos e quanto à possível elitização da advocacia, bem como, aqui mesmo no capítulo as intimações, sobre as incertezas criadas pela sua implantação nos diversos tribunais e pelas perplexidades trazidas pelo Código de 2015, com disposições que introduzem algumas regras que complementam e modificam as da Lei $\mathrm{n}$. 11.419 e muito, apresentam dificuldades de harmonização com o regime de intimações herdado do Código de 1973.

O temor é justificável, pois, no Estado do Rio de Janeiro, há estatísticas que atestam que possivelmente mais da metade de todos os processos existentes na justiça fluminense são patrocinados pela Defensoria Pública, que, até onde me é dado conhecer, não dispõe de equipamentos eletrônicos suficientes para atender a esse volume de demanda. 
Esta preocupação também é compartilhada por Bueno que ressalta a inquietação de não haver prejuízo para a prática do ato processual (BUENO, 2015, p. 168).

A finalidade para a distribuição do dever de equipar o Tribunal com um local onde faça o acesso digital está intrinsecamente vinculada ao acesso à Justiça, pois se o processo eletrônico facilita a comunicação de atos, confere-se maior celeridade, consequentemente as custas processuais serão menores e, ao final, haverá celeridade da resolução do conflito (PINHO, 2015, p. 422).

Esta acessabilidade tem matriz na proteção à dignidade da pessoa humana quando observada pelo prisma dos direitos das pessoas portadoras de deficiência, como salienta Medina, dando ênfase à violação de convenção internacional ratificada pelo Brasil que tem o dever de assegurar o acesso a novos sistemas e tecnologias da informação e comunicação (MEDINA, 2015, p. 333).

Esta argumentação foi a tese exposta na decisão proferida pelo Ministro Vice Presidente do Supremo Tribunal Federal Ricardo Lewandowski, na medida cautelar proferida nos autos do mandado de segurança n. 32.751-MC.

A decisão determina que o Conselho Nacional de Justiça assegure a advogada portadora de deficiência visual o direito de peticionar fisicamente enquanto o Conselho não vier a desenvolver sistema de processo eletrônico para portadores de deficiência ou possibilitar o acesso à tecnologia para o peticionamento de acordo com os padrões internacionais de acessibilidade.

Da decisão judicial se extrai o indicativo da proteção a igualdade no âmbito do peticionamento eletrônico:

(...) a partir do momento em que o Poder Judiciário apenas admite o peticionamento por meio dos sistemas eletrônico, deve assegurar o seu integral funcionamento, sobretudo, no tocante à acessibilidade.

Ocorre que isso não vem ocorrendo na espécie. Conforme narrado na inicial deste writ, o processo judicial eletrônico é totalmente inacessível às pessoas com deficiência visual, pois não foi elaborado com base nas normas internacionais de acessibilidade web.

Dessa forma, continuar a exigir das pessoas portadoras de necessidades especiais que busquem auxílio de terceiros para continuar a exercer a profissão de advogado afronta, à primeira vista, um dos principais 
fundamentos da Constituição de 1988, qual seja, a dignidade da pessoa humana (art. $1^{\circ}$, III, da CV).

Além disto, tal postura viola o valor que permeia todo o texto constitucional que é a proteção e promoção das pessoas portadoras de necessidades especiais.

Deve-se observar que a Corte considerou na análise da pretensão que o Supremo Tribunal Federal determina o peticionamento pela via eletrônica de forma exclusiva, na forma da Resolução n. 427, de 20 de abril de 2010, que no seu artigo 19, porém não houve a adoção dos meios essenciais para cumprir o conteúdo da Constituição Federal quanto ao respeito à igualdade, como também da convenção sobre os direitos das pessoas portadoras de deficiência.

A regulamentação do processo eletrônico feita pelo Conselho Nacional de Justiça, instalada na Recomendação n. 27, de 16 de dezembro de 2009, não tem a sua eficácia no que se refere "fossem tomadas as providências cabíveis para a remoção de quaisquer barreiras que pudessem impedir elou dificultar o acesso das pessoas com deficiência aos bens e serviços de todos os integrantes do Poder Judiciário".

Não havendo o respeito a condição desigual do advogado portador de necessidade pelo órgão judicial, não há respeito a isonomia. Por esta via de raciocínio, pode-se considerar que o Estado tem promovido a desigualdade.

Sobre a acessibilidade ao processo eletrônico, é importante avençar as regras atribuídas no Código de Processo Civil, com aquelas já fixadas pelo Conselho Nacional de Justiça, a exemplo da Resolução n 185 que determina aos órgãos do Poder Judiciário a instalação de equipamentos e auxílio técnico presencial às pessoas com deficiência e idosos. Muito embora, pouco se tenha avançado no que se refere a conceder tecnologias adequadas aos portadores de deficiência.

Desta forma, os órgãos deverão se estruturar no sentido de possuir dependências que acomodem o acesso ao peticionamento. Para facilitar a instalação, o ato prevê a celebração de convênios, com a Ordem dos Advogados do Brasil e outros integrantes da Administração Pública Direta ou Indireta, no sentido de dar forma a determinação da estrutura física com recursos humanos. 
No que tange ao acesso a deficientes visuais, Wambier (2015, p. 365) salienta que há previsão do Conselho Nacional de Justiça para a utilização de software que converta o texto em áudio como forma de ampliar a acessibilidade, contudo, esta via ainda não foi estruturada no Tribunal de Justiça Fluminense, não podendo ser avaliada no âmbito desta pesquisa.

Em ambas as hipóteses, trata o Conselho Nacional de Justiça de possibilitar formas implementadas para a prática eletrônica de atos processuais no sentido de ampliar os canais de processamento das demandas judiciais.

Esta adaptação não é inédita ao campo judiciário no que tange a forma de apresentação e processamento de demandas judiciais. Arthur Salles de Paula Moreira (THEODORO JUNIOR, OLIVEIRA, REZENDE, 2015, p. 157) apontou que na migração das peças processuais manuscritas para as datilografadas houve adequação às tendências de avanços sociais e técnicos:

Assim, o que se tem em verdade é uma nova via de processamento das demandas judiciais, que atém então, se devem a partir do meio físico e, agora, desmaterializando-se, passam para o meio eletrônico. Esta alteração já foi vivenciada, em menor escala, em diversas ocasiões. Foi assim, por exemplo, com a introdução das peças processuais datilografadas em substituição àquelas escritas à mão.

Tais sistemas virtuais têm por missão auxiliar no alcance dos princípios constitucionais dos serviços públicos e, mais especialmente, da jurisdição estatal, em especial, objetam aprofundar: direito de ação/acesso ao judiciário; celeridade processual; economia processual.

Nesta acomodação é possível apontar que o contínuo avanço tecnológico está vinculado à acessibilidade das informações e esta necessidade é migrável para a esfera do processo judicial, assim como os contatos foram informatizado pelos emails; livros e jornais, por notícias da internet; expressões que se tornaram virtuais face a uniformização do processo digital e sua eficiência.

Não obstante as virtudes atingidas com a vigência de um sistema normativo destinado a edição e produção de atos processuais do processo no Brasil, o maior problema pode ser visto com a impossibilidade de instalação das salas de atendimento da qual se ocupa a segunda parte deste trabalho. 


\section{DESVANTAGEM NO DESALINHO}

É certo que não haverá percalços com as constantes modificações e avanços tecnológicos que serão necessários a manutenção dos sistemas do processo judicial eletrônico, pois o Conselho Nacional de Justiça já vislumbrou esta hipótese ao preconizar que as alterações dos sistemas processuais não serão barreiras ao processo judicial eletrônico, devendo o Poder Judiciário promover as correspondentes alterações tecnológicas.

A resistência ao processo eletrônico se deu num primeiro momento quanto a impossibilidade de se manter um campo como o judiciário submetido a regras de tecnologia da informação ultrapassada.

Humberto Theodoro Junior pondera que o Conselho Nacional de Justiça disciplina a incorporação progressiva dos novos avanços tecnológicos (THEODORO JUNIOR, 2015, p. 477), o que conduz a reflexão de que as atualizações das tecnologias da informação não tornarão o sistema do processo eletrônico ultrapassado, pois estes serão modificados pelo Conselho quando da necessidade de sua modernização.

Desta forma, o que traz preocupação é a solução dada para falta de disponibilização dos sistemas que permite a prática de atos por meios eletrônicos, que é a autorização da sua realização por meios não eletrônicos.

Isto traz inquietação, a partir do momento de retração do processo eletrônico pela impossibilidade do Poder Judiciário adequar-se às normas criadas pelo Poder Legislativo, pois é esta dificuldade que gera a desigualdade. Para referendar a posição apontada, o relevo quanto ao debate da imposição do processo eletrônico e o custo operacional desta conversão encontra na voz de Leonardo Greco, quando discorre sobre a citação no processo eletrônico, inferindo para a geração de desigualdade (GRECO, 2015, p. 299/300).

Essa virtualização do processo e a imposição de exigências custosas para que os advogados exerçam o patrocínio judicial terão o nefasto efeito de elitização da advocacia. A meu ver, apenas alguns grandes escritórios de advocacia, que estarão aparelhados tecnologicamente, poderão cumprir todos os requisitos exigidos pela lei e atuar com eficácia no processo eletrônico.

Assim, os demais advogados e escritórios de pequeno porte terão grande dificuldade de acesso ao conteúdo dos processos, que não existirão mais na forma de papel não terão mais realidade física. 
Desta forma, ao não atender o Poder Judiciário a uma determinação do Código de Processo Civil e, consequentemente, do Conselho Nacional de Justiça, gera-se um desequilíbrio que não é tolerável pela Constituição da República no que diz respeito a isonomia entre os litigantes. Além disto, indica que o Poder Judiciário não adotou as medidas necessárias para a vigência do novo Código, o que aponta para a falta de acesso às novas tecnologias, como replicador de desigualdades, o que não é aceitável.

É com base nesta colocação que se preocupa com a falta do Estado no seu dever de conceder os equipamentos e o atendimento adequado para a acessibilidade ao processo eletrônico.

Então se visualizam duas situações distintas: a ausência de sistema capaz de garantir a igualdade a todos e a ausência de estrutura do Poder Judiciário para garantir o acesso ao processo eletrônico a todos os jurisdicionados. No que se refere à ausência de sistema, principalmente para os portadores de necessidades, o Poder Judiciário com esta postura omissiva vai gerar meios de enfatizar a desigualdade. Na outra esfera, também fomenta a desigualdade por que ao criar uma norma que acompanha a evolução tecnológica, não fornece os caminhos para aqueles que são excluídos digitalmente.

De qualquer forma, é a desigualdade a peça chave destas duas situações apontadas, seja pela falta da tecnologia, seja pela falta do atendimento. A solução normativa apontada é a prática dos atos por outro meio que não o eletrônico. Assim sendo, a distribuição do encargo de promover atos retorna para o Poder Judiciário, quando será por seus meios a digitalização da peça processual não eletrônica, com custo pelo Estado e praticado pelos servidores, em linha diametralmente oposta a pretendida quanto da regulamentação do processo eletrônico que foi o desafogamento do campo judiciário com a distribuição de carga dinâmica das atividades dos cartórios.

Em outras linhas, o Poder Judiciário deverá efetuar a digitalização e juntada das peças, causando um desvio da característica do processo eletrônico. Antonio José Carvalho da Silva Filho salienta que a redistribuição dos trabalhos burocráticos entre os participantes do processo como um dos principais objetivos que é a celeridade, sendo consequência do descumprimento do dever estatal (CUNHA, BOCHENEK, CAMBI, 2015, p. 416/417). 
Outro ponto que aborda a preocupação com a violação ao princípio constitucional da isonomia encontra repouso na ausência de garantia de acesso aos portadores de necessidade especiais que não possuem as condições do exercício profissional por não haver o auxílio técnico presencial para ajudar na consulta aos autos digitais em violação ao compromisso internacional assumido.

Para que se possa analisar se a falta da tecnologia irá ser um problema que causará transtornos maiores para a marcha processual, é preciso compreender como são vislumbradas outras hipóteses de tratamento para a sua falta. Augusto Tavares Rosa Marcacini elenca os problemas decorrentes das falhas de tecnologia em contraste com a utilidade da norma (WAMBIER, 2014, p. 614).

Outra razão relevante para a existência dessa norma, que lhe deve garantir sobrevida útil mesmo após superados os problemas momentâneos e conjunturais ligados à exclusão digital, é que sistemas informáticos não são imunes a falhas. A aplicação da tecnologia no ambiente processual traz riscos adicionais para as partes, dadas as suas peculiaridades. Em um cenário em que prazos rígidos lhes são atribuídos, sob pena de preclusão, não se poderia desconsiderar a muitas possibilidades de falhas - e são verdadeiramente muitas as coisas que podem dar errado, desde a infraestrutura local do escritório do advogado, o fornecimento de energia, a complexa rede pública de comunicação que é a Internet, até os próprios sistemas do Poder Judiciário - ao se informatizar o processo judicial e, essas questões todas ainda aguardam um tratamento legislativo mais específico. Neste sentido, o fornecimento de sistemas na sede do juízo servirá como caminho alternativo para contornar muitas falhas que podem ocorrer e prejudicar o cumprimento dos prazos, podendo a parte contar que, se tudo o mais deixar de funcionar, terá meios de praticar o ato dirigindo-se ao fórum mais próximo.

Em que pese o amor ao debate, em algumas unidades federativas, a hipótese apresentada pelo doutrinador de deslocamentos merece a consideração que entre uma comarca e outra haverá uma distância geográfica considerável e não se torna viável pensar no deslocamento do jurisdicionado sem que haja a perda do prazo.

São hipóteses deduzidas que não são funcionais em algumas unidades federativas onde o Tribunal de Justiça não conta com muitas comarcas, havendo dificuldade de se propor o deslocamento para outra que possua a acessibilidade ao sistema. Noutro polo, importante se faz considerar que a distância entre as comarcas é um fator prejudicial diante do congestionamento no fluxo de tráfego. 
O peso atribuído na inexistência de acesso ao meio eletrônico de prática de atos judiciais, de comunicação eletrônica e de assinatura eletrônica, evidencia a violação da paridade de tratamento (MARINONI, ARENHART, MITIDIERO, 2015, p. 248), não só em relação aos portadores de necessidades especiais, como também na falta da garantia objetiva de acesso.

Por esta razão, o que pode ser pensado como alternativa a não acessibilidade é a assinatura de convênios com outros entes da administração pública. Uma das alternativas ofertadas pela Resolução n 185 do Conselho Nacional de Justiça é o estabelecimento do convênio com a Ordem dos Advogados do Brasil ou outras associações representativas de advogados, bem como órgãos públicos.

Estes convênios têm por finalidade compartilhar responsabilidade na disponibilização de tais espaços, equipamentos e auxílio técnico presencial (WAMBIER, 2015, p. 365).

É oportuno reiterar o esclarecimento de que a criação das salas da Ordem dos Advogados do Brasil se dá na maioria dos fóruns, onde há disponibilidade de rede de computadores para a prática dos atos processuais, mas que estes espaços não possuem a mesma adequação para os jurisdicionados que possuem a capacidade de propor ações sem a assistência de um advogado, a exemplo do que ocorre nos juizados especiais cíveis, fazendários ou federais e que, não possuem o ambiente para a atuação.

Em que pese o posicionamento dos autores, a Ordem dos Advogados do Brasil ainda não tem oferecido aos jurisdicionados o atendimento para a prática de atos processuais. Não seria razoável admitir que a autarquia fornecesse o suporte técnico e de pessoal a quem não seja pertencente a sua jurisdição.

Não é forçoso considerar que o órgão judiciário não poderá fazer um convênio com associações de advogados para prestar o serviço que lhes foi atribuído. Esta delegação de poderes só admissível quando há cabimento em lei. Isto se deve ao fato das associações estarem destinadas a atender os interesses de seus filiados e não a uma gama incontável de pessoas a quem a norma é destinada. 
Para melhor aclarar esta posição, é preciso pontuar que a prática de atos processuais por meio eletrônico é uma tendência à desmaterialização, que é fruto das transformações sociais pelas quais a sociedade tem sido envolta nas últimas décadas.

Se o Estado almeja ampliar e modernizar a estrutura do campo judiciário e das demanda que por ali trafegam, não pode desconcentrar o encargo imposto a quem não possui, na essência, a obrigação de fornecer o acesso.

O papel da autarquia será de prestar assistência aos seus jurisdicionados, como cooperação, não sendo cabível o Poder Judiciário transferir este ônus para quem não possui o dever de paz e de influência.

Se há acessibilidade às informações e às comunicações, agilizando relações e produção intelectual, é reconhecida a atuação do Estado em se organizar e estruturar para receber estes impulsos.

Diante disto, compete aos Tribunais a criação e a regulamentação dos sistemas, sem deixar de acolher os princípios constitucionais inerentes aos serviços públicos, ou seja, promover a sua entrega com a observância do atendimento a maior gama de indivíduos, sem a criação de barreiras que possam incidir em mecanismos discriminatórios ou atentatórios à dignidade da pessoa humana.

A ideia inaugural do processo eletrônico é distribuir as responsabilidades no impulso da demanda judicial e se, o Estado, impõe a todos esta tarefa, que sejam conferidas pelo campo judiciário os meios para atingir a meta.

Ao impor condições igualitárias a todos sem fornecer as condições necessárias para minimizar as dificuldades impostas pelas condições culturais, sociais, estruturais, o Estado falha na concessão do acesso.

É oportuno compreender que se há imposição do Estado para a obtenção da prestação jurisdicional, é o Estado o primeiro a se adaptar a tendência de desmaterialização e virtualização do processo (THEODORO JUNIOR, OLIVEIRA, REZENDE, 2015, p. 157). 
É necessário compreender que os atos processuais praticados sob a forma eletrônica não estão especificamente destinados a aumentar os recursos do Poder Judiciário, mas sim simplificar o procedimento que assegure a tutela dos direitos.

O Código de Processo Civil de 2015 veio assumir esta postura, ao pretender garantir celeridade processual, sem se desvincular da segurança jurídica e garantia de um processo ético, de respeito e de colaboração entre os sujeitos. Por isto, o equilíbrio na garantia da paridade de armas feito pelo juiz é um dos pontos que mais merece a atenção da legislação (PINHO, 2015, p. 448).

Isto porque diante da falta de acessibilidade, o Poder Judiciário deve recompor a desigualdade evidenciada. Neste sentido, a cautela em se conferir uma alternativa a falha do Estado na concessão de garantia dos meios ao peticionamento eletrônico no âmbito do Judiciário a quem não tenha os equipamentos e conhecimentos para cumprir a implementação da informatização processual.

\section{CONCLUSÃO}

O estudo da paridade de armas no que diz respeito à instalação de meios para a prática no peticionamento eletrônico é necessário quando se observa a inexistência de recursos tecnológicos para a sua realização.

Dois pontos são relevantes na realização da paridade de armas no processo eletrônico: o primeiro é inerente à ausência do espaço físico equipado e com a assistência técnica ideal para a sua concretização. No segundo ponto, tem correlação com os portadores de necessidades especiais que não têm um sistema adaptado conforme a previsão legal e com a convenção internacional, ambas pertinentes à defesa dos direitos de pessoas com deficiência.

Não se trata de uma opção daquele que necessita recorrer ao órgão judiciário, mas sim uma exigência feita pelo Estado para que a tramitação processual pela via desmaterializada possa garantir uma prestação jurisdicional mais célere, mais econômica e menos burocratizada. 
No entanto, no que se refere à concessão dos meios objetivos ao acesso, o Estado não tem dedicado a implantação de condições para a sua prática por aquela parcela da população que não possui os recursos necessários para o seu desenvolvimento.

Neste curso, o Conselho Nacional de Justiça regulamentou através da Resolução n. 185, anterior ao Código de Processo Civil, que, na ausência das condições materiais para a instalação de ambiente adequado ao processo eletrônico, com computadores, sistema de informática, scanners, equipe técnica hábil para auxiliar na prática de atos processuais por meio eletrônico, o órgão judiciário poderá efetuar convênios com a Ordem dos Advogados do Brasil, associações de advogados, entes da administração pública, enfim, delegar a gestão de processos.

Porém, um recorte deverá ser feito quanto à competência da $\mathrm{OAB}$ e das associações de classe, pois não cabe a estes órgãos a realização de assistência a jurisdicionados que não sejam inscritos nos quadros da autarquia. Gerando, num sentido mais amplo, um conflito de interesses, pois, nas causas em que o valor seja compatível com o rito dos juizados especiais cíveis, fazendários e federais, estaria atuando em desvio de função.

Isto por que a Ordem dos Advogados do Brasil estaria atendendo individualmente a sociedade naquilo que poderia ser atividade do advogado que lhe é jurisdicionado.

Por outra via, é possível apontar que o papel do Estado é romper com as barreiras de desigualdade e não gerar conflitos de interesses, já que estaria atuando em conjunto com seus jurisdicionados na defesa dos pilares do Estado Democrático de Direito, que é a sociedade justa.

Pensar na ruptura das condições que fixam a desigualdade, neste aspecto, é identificar que a falha no cumprimento da preleção dos artigos 198 e 199 do Código de Processo Civil é um indicativo de que não houve a preparação pelo órgão judiciário para o desenvolvimento das políticas implementadas pela Lei Federal n. 13.105/2015.

É oportuno identificar que o Conselho Nacional de Justiça, desde a sua criação, vem se estruturando para o desenvolvimento dos métodos de resolução da crise do Poder Judiciário. 
No entanto, neste singular ponto, não houve a percepção de que uma grande parcela da população não está tecnicamente habilitada a manusear os sistemas do processo eletrônico, seja pela ausência de conhecimento, seja pela restrição que o sistema oferece.

Ampliar as matrizes pelas quais se possam ofertar uma prestação jurisdicional mais célere é o que a doutrina tem inclinado a suscitar, sempre observando que a desigualdade existente se faz tanto por aspectos culturais, quanto por aspectos econômicos. Ao largo de mais de vinte que a legislação processual civil passou por transformações destinadas a adequação ao avanço da sociedade, todas as modificações inseridas foram alinhadas a estrutura do campo judiciário, mas nenhuma delas tão profunda quanto a Lei Federal n. $13.105 / 2015$.

Não há outras soluções aplicáveis no caso de inexistência da disponibilidade dos mecanismos de acessibilidade, a não ser a permissão de realização dos atos processuais por outras vias, neste caso, o meio físico.

Daí desponta um grande retrocesso, pois o peticionamento será feito sem ônus para a parte, sendo da responsabilidade do órgão judiciário a digitalização e desmaterialização do processo, ou seja, o retorno ao estado anterior.

Como o Poder Judiciário de todo país tem se esforçado na informatização do processo, o sistema informatizado para ser moderno e eficaz deve garantir a entrega de uma prestação jurisdicional mais célere.

Todavia, deve fazer este aprimoramento pautado na igualdade e na dignidade da pessoa humana, o que deverá ser feito com a adoção de medidas para o complexo de desmaterialização do processo.

A ausência de métodos para suprir estas deficiências na estrutura física dos órgãos judiciários deve ser um padrão de exceção, pois não guarda coerência com o valor Justiça da qual a prestação jurisdicional deva ser permeada e sempre observada pelo juiz.

A análise dos indicativos de tratamento desigual nas situações onde haja a limitação a utilização dos sistemas de prática de atos processuais por meio eletrônico deve ser uma medida ponderada se diagnosticada pelo juiz. 
Levando a guisa de fundamento, não há até o momento, nenhum Enunciado do Fórum Permanente dos Processualistas Civis sobre a matéria, o que tornará menos uniforme o entendimento acerca dos limites de sua aplicabilidade, ou ainda os parâmetros do seu reconhecimento.

Não há na página eletrônica do Tribunal de Justiça Fluminense qualquer informativo à sociedade acerca da existência das salas de atendimento nas comarcas do Estado do Rio de Janeiro.

Igual consideração deve ser feita, na busca pelo sítio do Conselho Nacional de Justiça que não instruiu a comunidade jurídica com dados sobre a eficácia dos artigos 198 e 199 do Código de Processo Civil.

A falha do Estado na garantia objetiva do acesso não deve ser motivo para a declaração de preclusão ou de obstáculos à prestação jurisdicional, considerando não só os valores culturais da sociedade, mas também criar meios de fornecer as armas para que possam todos os que necessitam do Poder Judiciário tenham acesso as estruturas adequadas.

\section{REFERENCIAS}

BRASILIA. Conselho Nacional de Justiça. Recomendação 27. Disponível em: http://www.cnj.jus.br/atos-normativos?documento=873. Acesso em 03. Abr.2016. BRASILIA. Conselho Nacional de Justiça. Resolução n. 185. Disponível em: http://www.cnj.jus.br///images/atos_normativos/resolucao/resolucao_185_18122013_0701201 4161739.pdf. Acesso em 03.Abr.2016.

BRASILIA. Supremo Tribunal Federal. Medida Cautelar em Mandado de Segurança n. 31.751/DF. Relatoria Ministro Celso de Mello. Disponível em: http://www.stf.jus.br/portal/processo/verProcessoAndamento.asp?incidente=4522711. Acesso em 03. Abr.2016.

BRASILIA. Supremo Tribunal Federal. Resolução n. 427. Disponível em: http://www.stf.jus.br/ARQUIVO/NORMA/RESOLUCAO427-2010.PDF. Acesso em 03. Abr.2016. 
BUENO, Casio Scarpinella. Novo Código de Processo Civil anotado. São Paulo: Saraiva, 2015 .

CUNHA, José Sebastião Fagundes. (coordenador geral). BACHENEK, Antonio Cesar. CAMBI, Eduardo. Código de Processo Civil comentado. São Paulo: Revista dos Tribunais, 2016.

GRECO, Leonardo. Instituições de processo civil. Introdução do Direito Processual Civil. Volume I. 5a edição revista, atualizada e ampliada. Rio de Janeiro: Forense, 2015.

MARINONI, Luiz Guilherme; ARENHART, Sergio Cruz; MITIDIERO, Daniel. Novo curso de processo civil: tutela dos direitos mediante procedimento comum. Volume II. São Paulo: Revista dos Tribunais, 2015.

Novo código de processo civil comentado. São Paulo: Revista dos Tribunais, 2015.

MARTINS, Fabrício Irun Silveira. Novo Código de Processo Civil Comparado. Leme: CL EDIJUR, 2015.

MEDINA, JOSÉ Miguel Garcia. Direito processual civil moderno. São Paulo: Revista dos Tribunais, 2015.

PINHO, Humberto Dalla Bernardina de. Direito Processual civil contemporâneo. Volume I: teoria geral do processo. $6^{\text {a }}$ edição. São Paulo: Saraiva, 2015.

THEODORO JUNIOR, Humberto. Curso de direito processo civil. Teoria geral do direito processual civil, processo de conhecimento e procedimento comum. Vol. I. 56 $6^{\mathrm{a}}$. Ed. rev., atual. e ampl. Rio de Janeiro: Forense, 2015.

OLIVEIRA, Fernanda Alvim Ribeiro. REZENDE, Ester Camila Gomes Norato. Primeiras lições sobre o novo direito processual civil brasileiro (de acordo com o Novo Código de Processo Civil, Lei 13.105, de 26 de março de 2015). Rio de Janeiro: Forense, 2015 .

WAMBIER, Teresa Arruda (et alli). Primeiros comentários ao novo código de processo civil: artigo por artigo. $1^{\text {a }}$. edição. São Paulo: Revista dos Tribunais, 2015. 
WAMBIER, Teresa Arruda (et alli). Breves comentários ao novo código de processo civil: artigo por artigo. São Paulo: Revista dos Tribunais, 2015.

WAMBIER, Luiz Rodrigues. TALAMINI, Eduardo. Curso Avançado de Processo Civil. Vol. 1. Teoria geral do processo e processo de conhecimento. $15^{\mathrm{a}}$ edição, revista e atualizada. São Paulo: Revista dos Tribunais, 2015. 